\title{
Rancang Bangun Sistem Smart Locker Menggunakan Voice Access Berbasis Arduino Mega
}

\author{
Ferry Sudarto $^{1}$, Juni Aldo Zuntama ${ }^{2}$, Ikbal Budiono ${ }^{3}$ \\ 1,2,3Program Studi Sistem Komputer Universitas Raharja \\ Email : '1 ferry.sudarto@ raharja.info, ${ }^{* 2}$ Juni.aldo@raharja.info, ${ }^{3}$ ikbal.budiono@ raharja.info
}

\begin{abstract}
Abstrak
Pentingnya keamanan membuat semua orang harus menjamin keamanan atas segala sesuatu yang termasuk dalam dirinya, baik dari aktivitas maupun aset yang dimilikinya. Nilai suatu aset memiliki dorongan bagi setiap orang untuk menerapkan sistem keamanan sebagai perlindungan. Salah satunya pada lemari Loker yang umumnya masih menggunakan sistem penguncian manual. Maka dibutuhkan Smart Locker yang menggunakan teknologi mikrokontroler dan Modul GSM yang digabung dengan aplikasi yang mendukung seperti berbasis android. Tujuan penelitian yang dilakukan agar merancang sistem keamanan dengan pintu lemari loker menggunakan Voice Access berbasis arduino mega. Ketika loker dipaksa dibuka maka buzzer akan memberitahukan kepada pemilik bahwa pintu loker dibuka melalui pesan singkat SMS dari jarak jauh dan modul GSM bertujuan untuk membuka dan mengunci pintu loker melalui pesan SMS dari jarak jauh dimana Mode komunikasi SMS menggunakan modul GSM. Voice Access bertujuan membuat hak akses Anda saat akan mengaktifkan sistem alat loker menggunakan perintah suara sistem $O n$ dan $O f f$. Tidak semua orang dapat menggunakan loker ini karena hanya beberapa saja yang dapat mempergunakannya dengan akses yang telah diberikan dengan menginput password yang benar saat membuaka pintu loker. Locker lock dapat dibuka jika password yang dimasukkan dengan benar, kemudian password berhasil dan selanjutnya akan disimpan dan ditampilkan padadi layar LCD sebagai interface.
\end{abstract}

Kata kunci: smart locker, password, arduino mega, locker lock

\begin{abstract}
The importance of security makes everyone must ensure the security of everything that is included in him, both from the activities and assets he owns. The value of an asset has an incentive for everyone to implement a security system as protection. One of them is in the locker cabinet which generally still uses a manual locking system. So a Smart Locker is needed that uses microcontroller technology and a GSM Module combined with supporting applications such as Android-based. The purpose of this research is to design a security system with locker cabinet doors using Arduino Mega-based Voice Access. When the locker is forced to be opened, the buzzer will notify the owner that the locker door is opened via SMS short message remotely and the GSM module aims to open and lock the locker door via SMS message remotely where SMS communication mode uses the GSM module. Voice Access aims to make your access rights when you want to activate the locker system using the system voice command On and Off. Not everyone can use this locker because only a few can use it with the access given by entering the correct password when opening the locker door. The locker lock can be unlocked if the password is entered correctly, then the password is successful and then it will be stored and displayed on the LCD screen as an interface.
\end{abstract}

Keywords: smart locker, password, arduino mega, locker lock 


\section{PENDAHULUAN}

Pentingnya keamanan membuat semua orang harus menjamin keamanan atas segala sesuatu yang termasuk dalam dirinya, baik dari aktivitas maupun aset yang dimilikinya. Nilai suatu aset memiliki dorongan bagi setiap orang untuk menerapkan sistem keamanan sebagai perlindungan. Namun, masalah keamanan masih terjadi di mana-mana dan dengan berbagai cara. Salah satunya bisa terjadi di lemari loker, sebagai tempat menyimpan dan mengamankan barang-barang penting, serta menjadi salah satu objek tindak kriminal seperti perampokan atau pencurian. Pada kasus ini pengamanan loker saat ini penguncian masih manual menggunakan kunci yang bisa saja di duplikat oleh orang. Maka dibutuhkan sebuah sistem Smart Locker yang menggunakan Voice Access berbasis arduino mega, dimana akses suara dapat meminimalisir pembukaan loker secara paksa oleh orang yang tidak bertanggung jawab. Karena hanya pemilik lokerlah yang dapat mengakses dengan suara pemilik yang terekan oleh sistem.

\section{TINJAUAN PUSTAKA}

Pendapat Yudhanto dan Azis (2019:142)[1] Arduino Mega merupakan mikrokontroler Arduino yang memiliki spesifikasi lebih tinggi, yang dilengkapi dengan penambahan pin digital, pin analog, port serial dan lainnya. Arduino Mega didasarkan pada ATmega1280 dengan 54 input loutput digital.

Pendapat Pradana dan Wiharto dalam Jurnal EL Sains (2020:56)[2] Solenoid door lock merupakan sebuah pelindung (keamanan) pintu menggunakan solenoid dalam membuka atau menutup (mengunci) pintu secara elektronik. Solenoid merupakan kumparan elektromagnetik yang di desain khusus yang beroperasi dengan tegangan $12 \mathrm{Vdc}$.

Pendapat dari Parastiwi, dkk (2018:114)[3] LCD 16X2 merupakan LCD yang mempunyai batas maksimum 16 digit horizontal dan 2 digit vertical yang dihubungkan ke PORT B pada mikrokontroller AtMega16 dengan merubah data ASCII menjadi data karakter yang akan ditampilkan pada display LCD.

\section{LITERATURE REVIEW}

1. Hazarah [4], "Rancang bangun Smart Door Lock Menggunakan QR Code dan Solenoid". Pada penelitian ini menggunakan mikrokontroler Arduino Uno sebagai otak dari solenoida, dan Android sebagai pengontrol QR Code reader. Pembaca Kode QR di Android dijalankan menggunakan aplikasi pihak ketiga yaitu Barcode Scanner. Pemrograman Arduino dilakukan dengan menggunakan Arduino IDE. Bluetooth $\mathrm{HC} 05$ digunakan untuk menghubungkan aplikasi pemindai kode batang di Android dengan Arduino. Alat pengujian dijalankan pada platform Android Jelly Bean dan komponen perangkat keras dan lunak dapat berjalan dengan baik. Hasil penelitian dijelaskan dalam bentuk alat kunci pintu rumah perancangan secara otomatis menggunakan $Q R$ Code dengan aplikasi Barcode Scanner dan Arduino sebagai solenoid kontrol.

2. Pradana dan Wiharto [2][5], "Rancang Bangun Smart Locker Menggunakan Rfid Berbasis Arduino Uno". Loker dibuat dengan sistem keamanan ganda dengan menggunakan keypad dan RFID sebagai kode akses. LCD sebagai tampilan urutan penggunaan alat, LED sebagai indikator dan Arduino Uno sebagai pengontrol dan pengolah data. Sistem keamanan loker dibagi menjadi dua, yaitu kode akses pin dan kode akses pin dengan identifikasi RFID.

3. Nugroho [6], "Rancang Bangun System Smart Door Lock Berbasis SMS (Short Message Service).". pada penelitian ini peneliti merancang sebuah sistem smart door lock berbasis SMS yang dapat digunakan untuk mengendalikan dan memberikan informasi pada pintu 
rumah yang praktis dan efisien, dengan menggunakan smartphone sebagai pengontrol dan monitoring pintu rumah.

\section{METODE PENELITIAN}

A. Pengumpulan data

Untuk pengumpulan data penelitis menggunakan beberapa metode yaitu:

- Metode Observasi, dalam metode ini peneliti harus mereview apa yang sedang diteliti yaitu melakukan observasi langsung dengan terlibat dalam proses pembuatan sistem yang ada. Kemudian dari observasi tersebut, peneliti mengumpulkan data-data yang dibutuhkan untuk dianalisis dalam rangka mengembangkan sistem.

- Metode Wawancara, dalam metode ini peneliti harus melakukan sesi tanya jawab dengan narasumber salah satunya adalah owner tempat peneliti melakukan penelitian. Metode ini digunakan untuk mendapatkan data yang relevan sesuai dengan kebutuhan sistem.

B. Metode Prototipe

Peneliti menggunakan metode prototipe evolutionary, karena sistem evolutionary atau produk aktual dipandang sebagai evolusi dari versi awal yang sangat terbatas menjadi produk akhir.

\section{HASIL DAN PEMBAHASAN}

\subsection{Flowchart Sistem Yang Diusulkan}

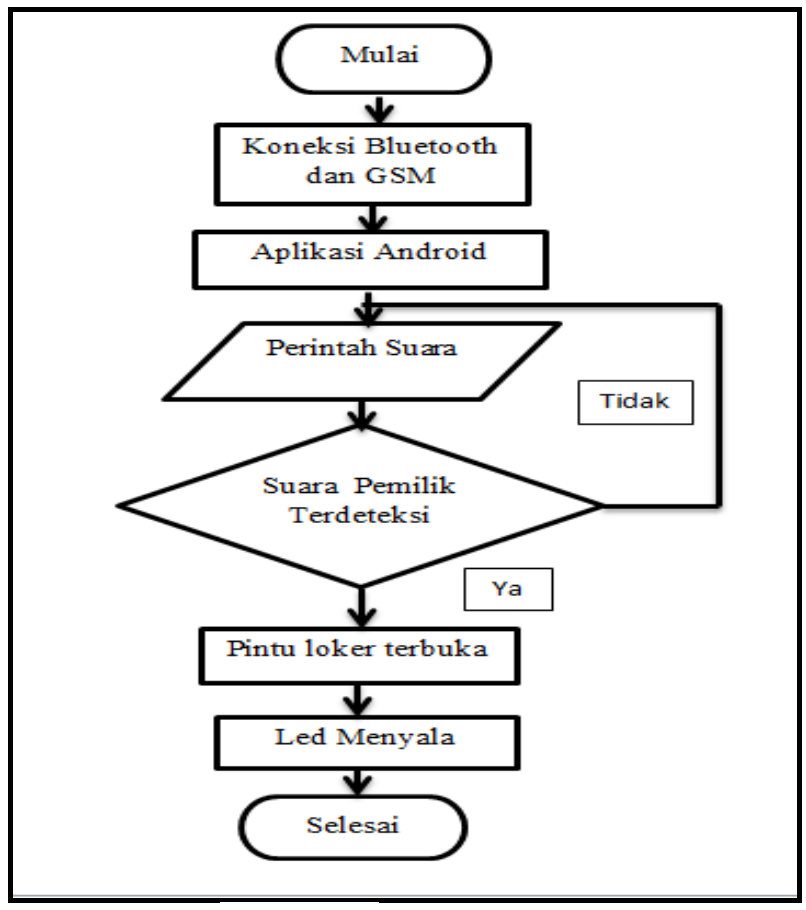

Gambar 1 Flowchart Sistem Yang Diusulkan

Ketika menjalankan program pertama periksa koneksi bluetooth dan modul GSM. Saat melakukan sistem on off di locker system kita harus menjalankan koneksi bluetooth via smartphone sebagai via voice system on off. Saat terkoneksi dengan bluetooth kita 
dapat menggunakan modul GSM sebagai pengunci dan membuka loker melalui sms dari jarak jauh. Ketika perintah suara tidak terdeteksi, akan kembali ke perintah suara untuk mendeteksi suara pemiliknya. Saat terdeteksi, pintu loker akan terbuka dan LED menyala.

\subsection{Diagram blok}

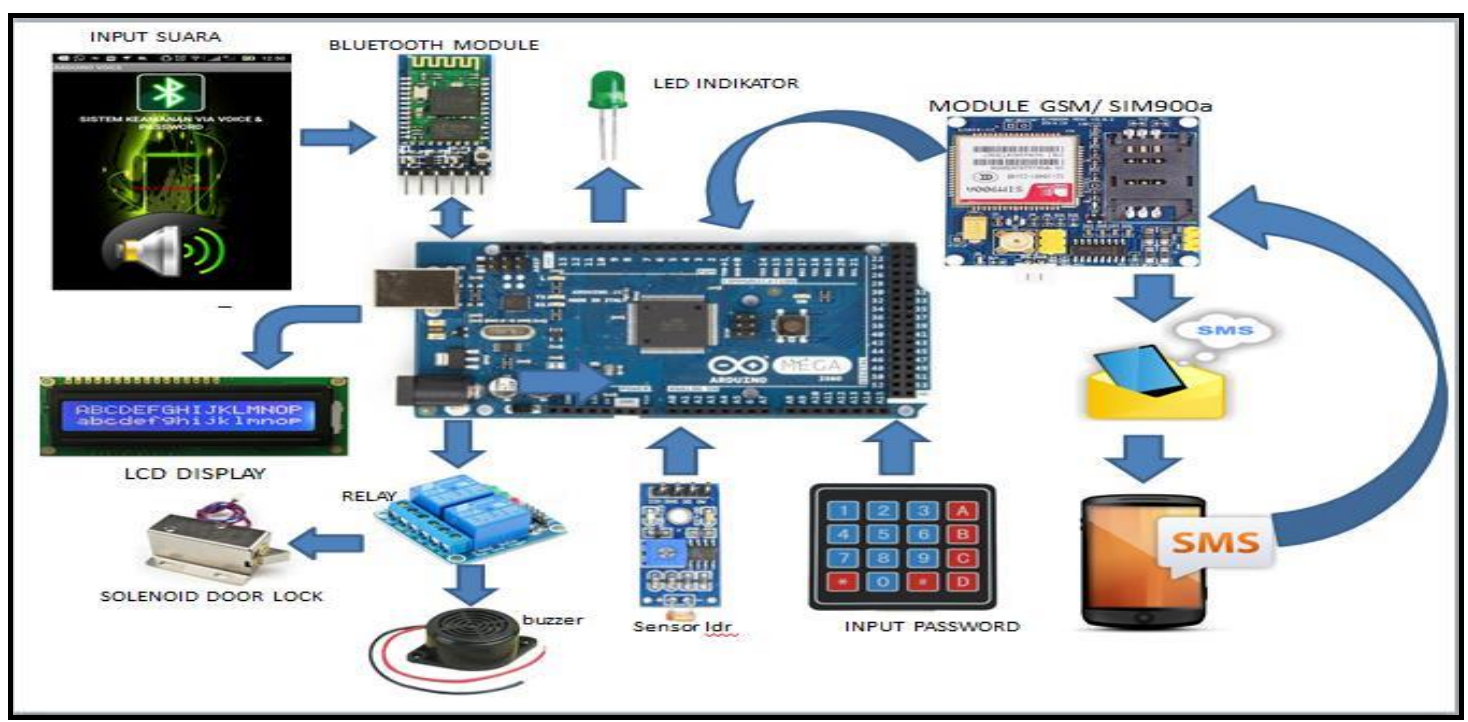

Gambar 2 Rangkaian Diagram Blok

Pada diagram blok diatas terdapat input suara, Bluetooth module, LED indicator, modul GSM/SIM900a untuk mengirimkan SMS, input password untuk membuak loker, sensor ldr untuk mengetahui apakah loker terbuka/tertutup, relay, solenoid door lock, buzzer (pemberitahuan kepada pemilik bahwa loker terbuka), LCD Display.

\subsection{Cara Kerja Alat}

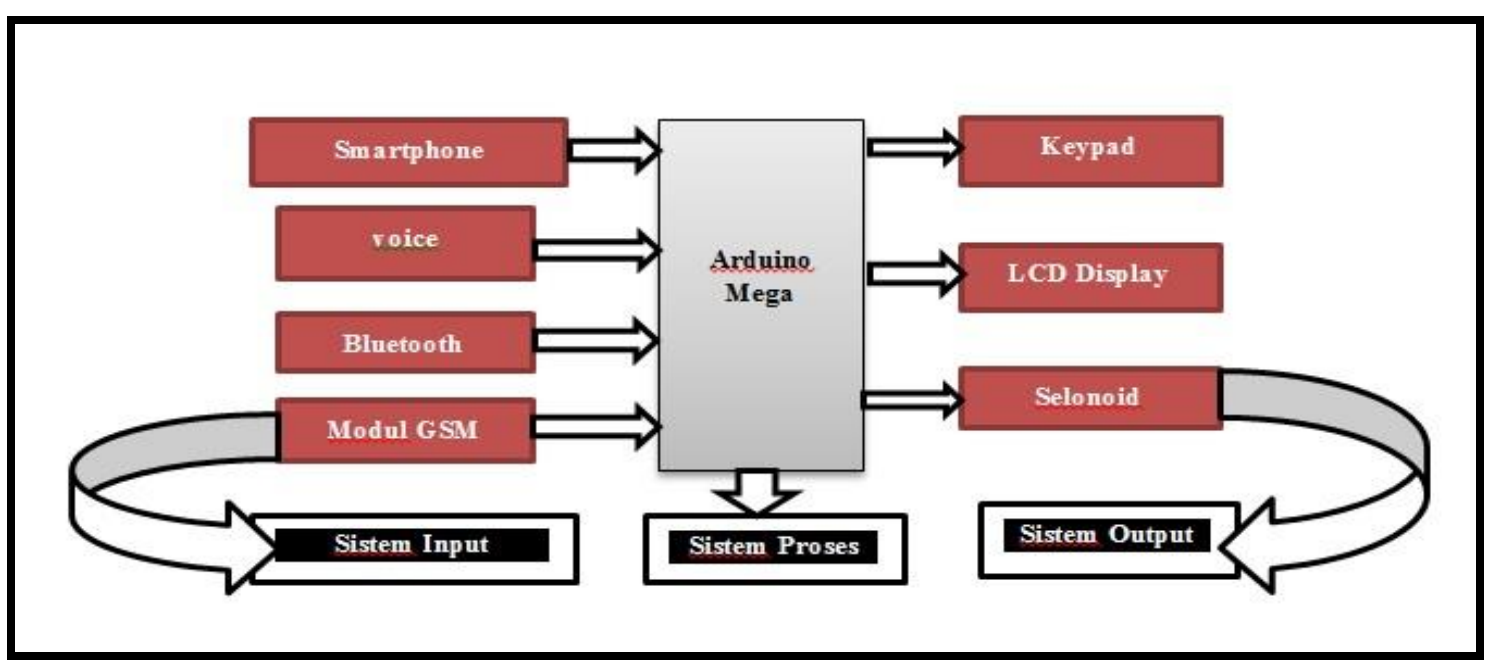

Gambar 3 Diagram Cara Kerja

Berdasarkan cara kerjanya dan pengontrolan pintu loker dibuat :

1. Sistem input diatas menjelaskan bahwa perintah suara digunakan untuk membuka dan menutup loker melalui smartphone yang terhubung dengan Bluetooth dan dijaga keamanannnya menggunakan modul GSM. 
2. Sistem proses menggunakan Arduino Mega untuk membuka dan menutup loker dengan perintah suara.

3. Sistem keluaran menggunakan Keypad untuk memasukkan password dan akan ditampilkan pada LCD Display sebagai keluaran/tampilan dan dikontrol melalui rangkaian relay untuk mengontrol Selonoid dalam mengunci loker, perintah suara digunakan untuk membuka dan menutup loker. Setelah menginput suara yang sudah diucapkan. Maka Arduino Mega akan memprosenya, selanjutnya Selonoid membuka dan menutup loker secara otomatis sesuai dengan perintah suara yang sudah tersimpan.

Dalam pembuatan bentuk skema dibutuhkan aplikasi fritzing dalam merancang rangkaian elektronik guna mendukung library Arduino seperti gambar dibawah ini:

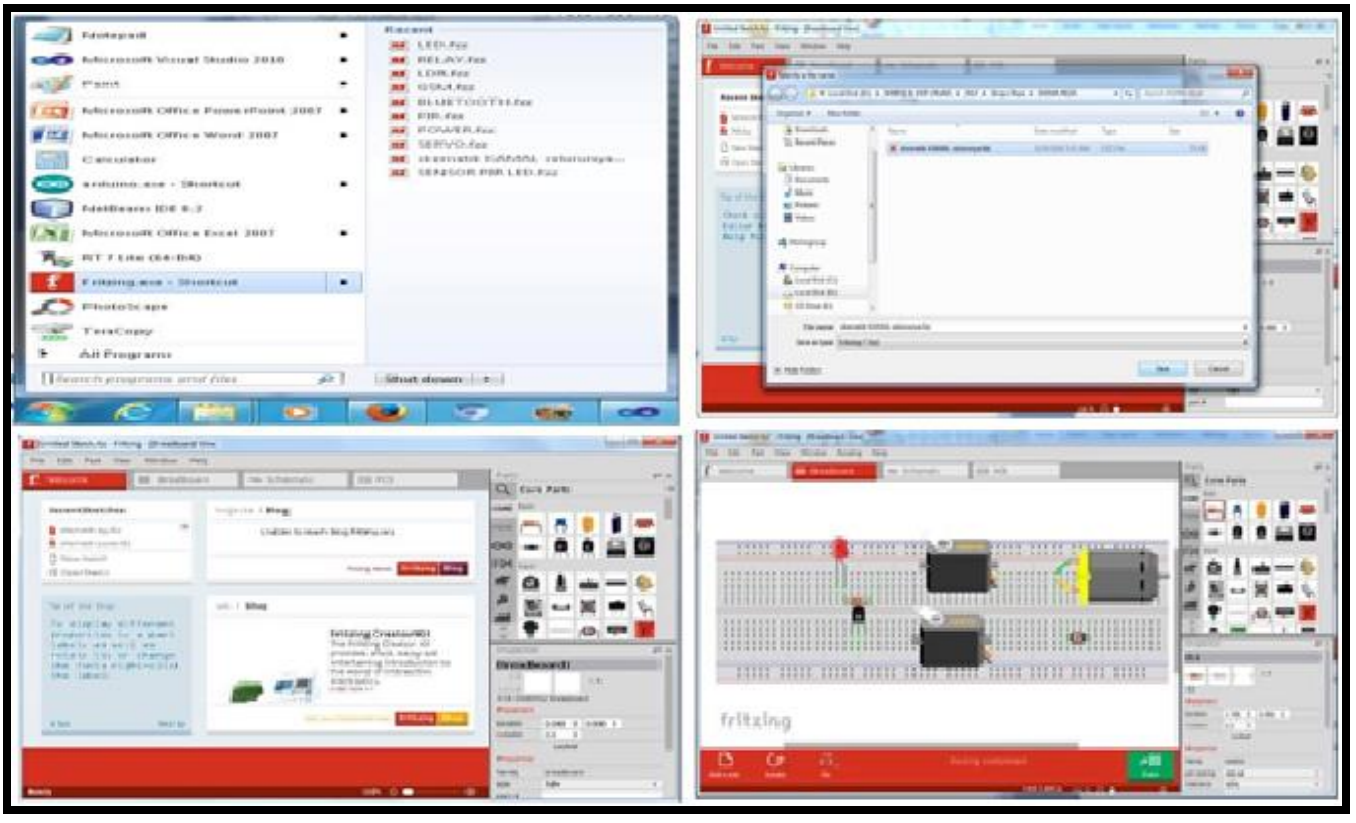

Gambar 4 Project pada Fritzing

\subsection{Rangkaian Keseluruhan}

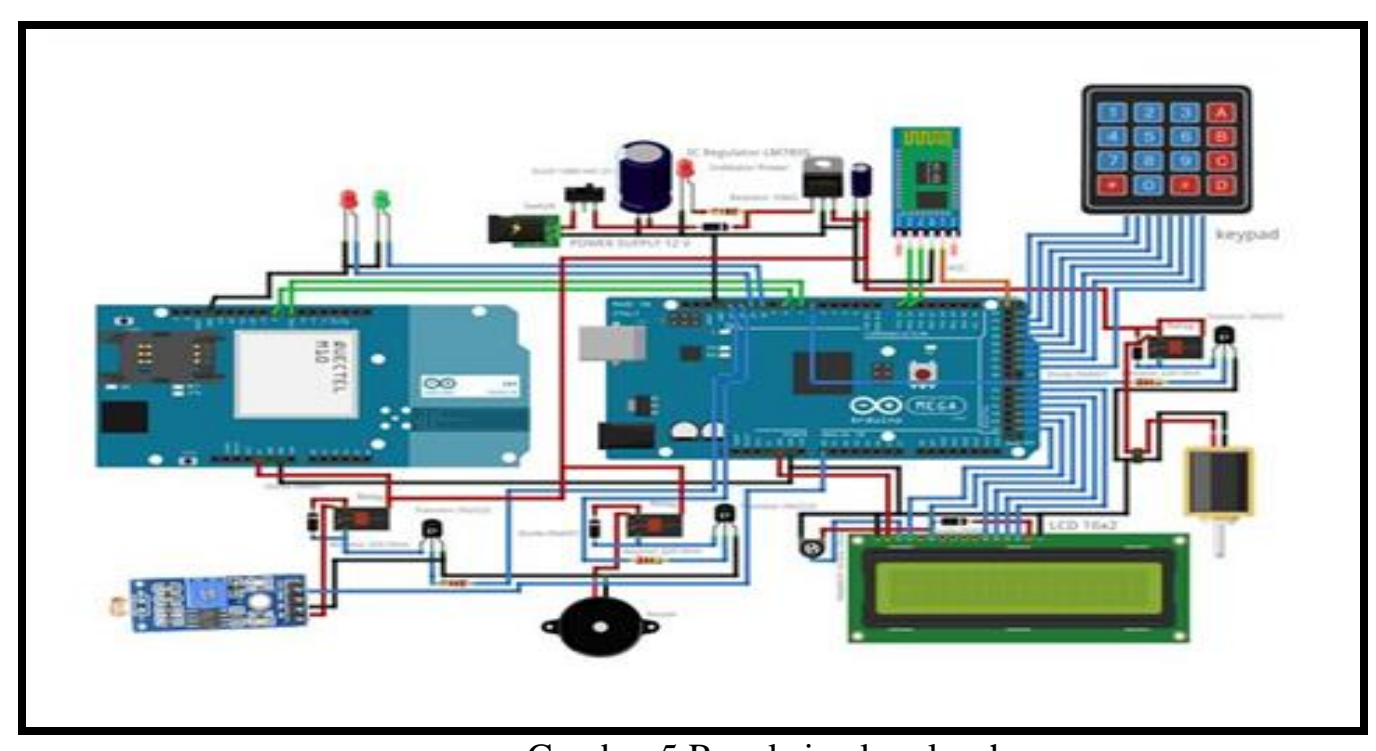

Gambar 5 Rangkaian keseluruhan 
Deskripsi jalur-jalur gambar diatas :

a. Garis merah sebagai arus positif $(+)$

b. Garis hitam sebagai arus negatif (-)

c. Garis biru sebagai jalur data.

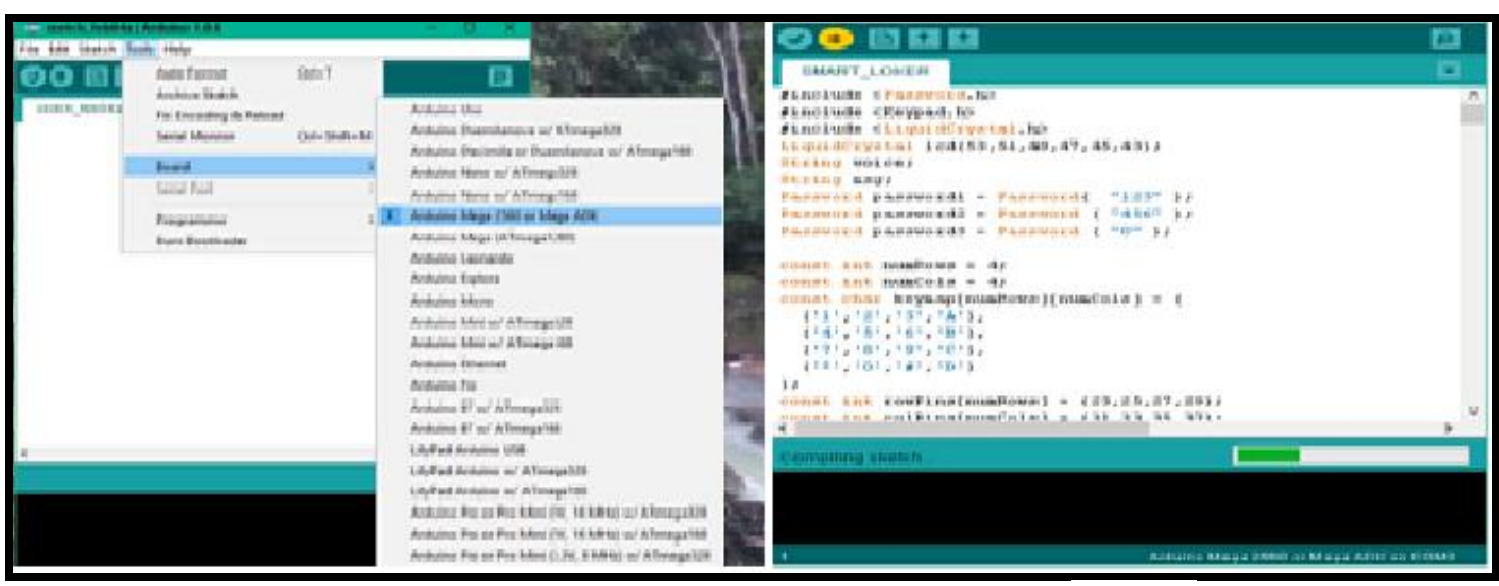

Gambar 6 Mengupload Program Ke Dalam Modul Arduino

Pilih jenis board, kemudian memasukkan program ke dalam mikrokontroler menggunakan modul Arduino Mega. Setelah langkah diatas dirasa sudah benar maka sistem mikrokontroler siap digunakan dan bekerja dengan baik.

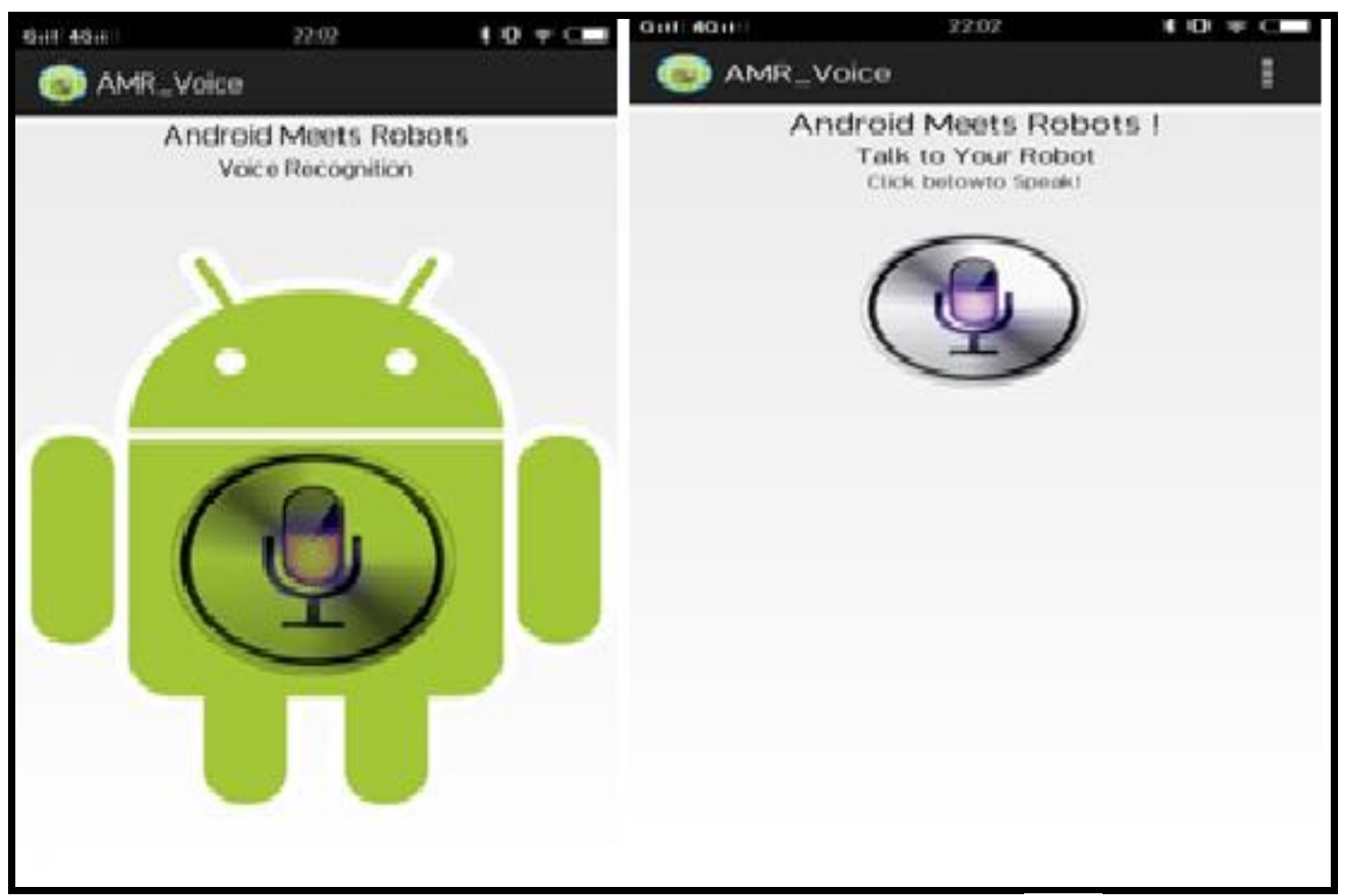

Gambar 7 Tampilan Gambar Aplikasi Sistem Via Voice

Gambar diatas merupakan aplikasi sistem via voice yang digunakan untuk mengaktifkan sistem alat loker menggunakan perintah suara sistem $O n$ dan $O f f$ 


\subsection{Rangkaian Selonoid Door Lock Menggunakan SMS Buka Tutup Loker}

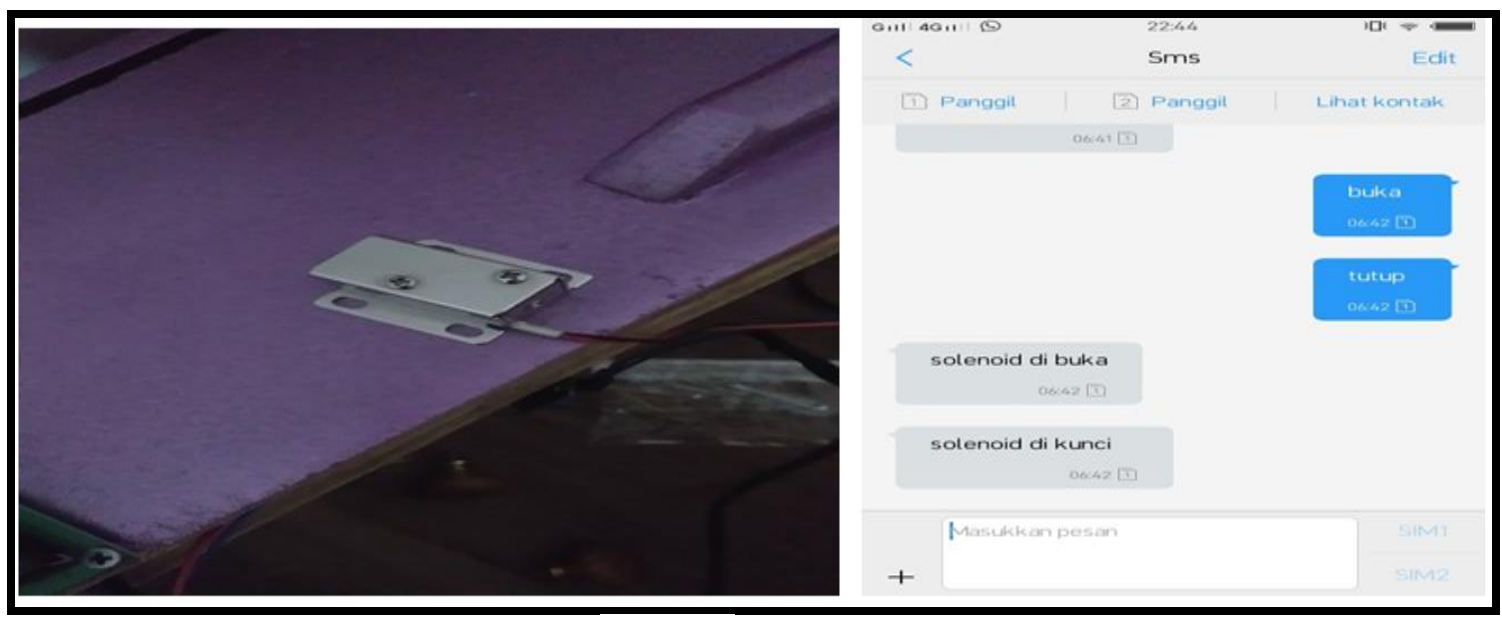

Gambar 8 Rangkaian Selonoid Door Lock Menggunakan SMS

pada gambar di atas kemudian masukkan codingan tersebut ke dalam library arduino sebagai berikut:

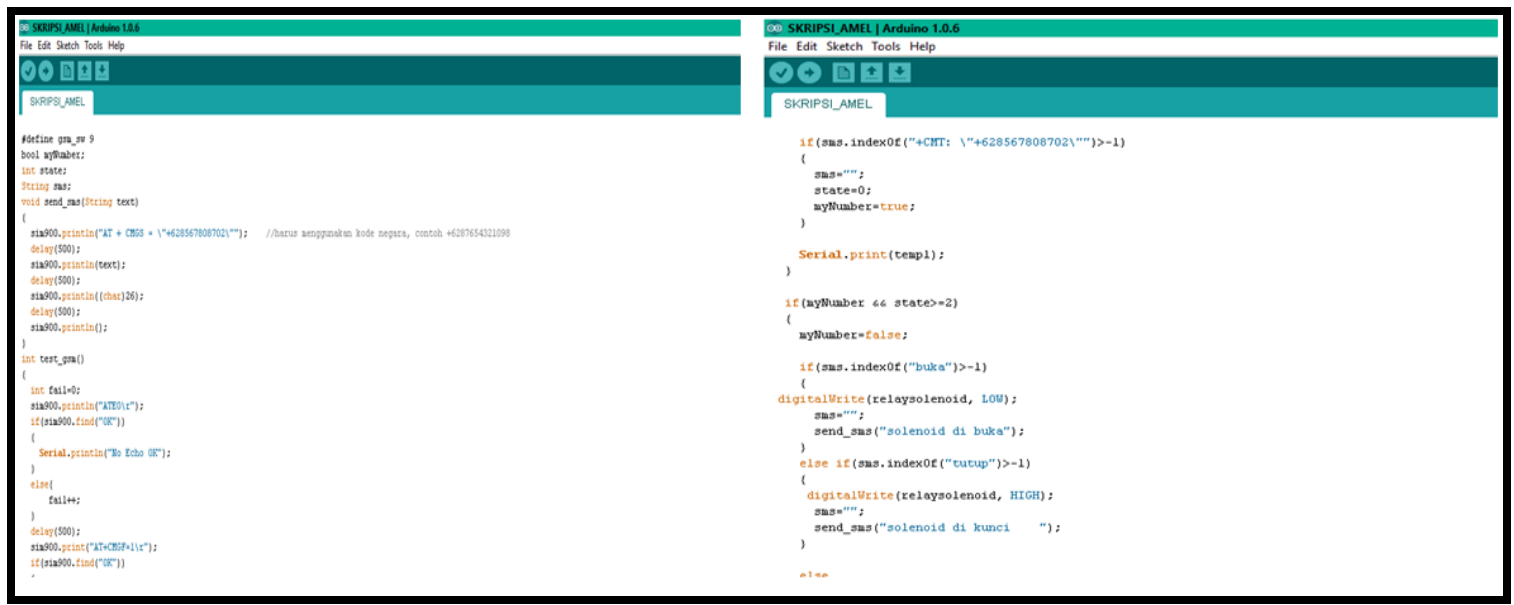

Gambar 9 Program Modul GSM Melalui Pesan SMS

Pada gambar pemrograman di atas, ketika ingin memverifikasi informasi pada modul GSM dengan memasukkan nomor telepon pemilik untuk membuka dan menutup melalui pesan SMS

\section{KESIMPULAN}

Untuk Smart Locker ini menggunakan berbagai komponen antara lain Arduino Mega, Sensor LDR, Selonoid Door Lock, Relay, Keypad, Buzzer dan Smartphone. Dengan adanya Smart Locker ini maka lebih aman saat menyimpan barang-barang dan dapat dipublikasikan dalam bentuk loker berbasis digital. Smart Locker dapat bekerja melalui jaringan bluetooth dan juga pada jaringan modul GSM. 


\section{SARAN}

Disarankan agar Sistem Smart Locker ini dapat dikembangkan lebih lanjut agar dapat terus memberikan manfaat bagi penggunanya.

\section{DAFTAR PUSTAKA}

[1] Yudhanto, Y., \& Azis, A. 2019. Pengantar Teknologi Internet Of Things (IoT). Surakarta: UNS Press

[2] Pradana, V., \& Wiharto, H, L. 2020. Rancang Bangun Smart Locker Menggunakan Rfid Berbasis Arduino Uno. Jurnal EL Sains, 2(1) 55-61

[3] Parastiwi, A., Putri, R, I., Adhisuwigno, A., \& Rifa'I, M. 2018. Photovoltaic Terapan: Teknologi dan Implementasi. Malang : Polinema Press

[4] Hazarah, A. 2017. Rancang bangun Smart Door Lock Menggunakan QR Code dan Solenoid. Jurnal Teknologi Informatika dan Terapan, 4(1) 5-10

[5] Pradana, V., \& Wiharto, H, L. 2020. Rancang Bangun Smart Locker Menggunakan Rfid Berbasis Arduino Uno. Jurnal EL Sains, 2(1) 55-61

[6] Nugroho, A.2019. Rancang Bangun System Smart Door Lock Berbasis SMS (Short Message Service). Skripsi. Program Studi Pendidikan Teknik Elektro. Fakultas Teknik. Universitas Negeri Semarang 